\title{
Can hepatitis $C$ virus infection be cured with complementary and alternative medicine?
}

\begin{abstract}
Hepatitis $\mathrm{C}$ virus (HCV) infection is among the main causes of chronic liver disease, causing related morbidity and mortality, globally. While the prescription of direct acting antiviral drugs (DAAs) has led to increased cure rates for many patients with $\mathrm{HCV}$, there is still a demand for more promising treatments. Certain natural compounds can decrease the viral load of HCV and prevent further liver damage. While, some of these herbs do not have any therapeutic efficacy and may cause detrimental effects on the patients.
\end{abstract}

Volume 12 Issue 6 - 2021

\author{
Alireza Ebrahimi,' Sedigheh Ebrahimi \\ 'Student Research Committee, Shiraz University of Medical \\ Sciences, Iran \\ ${ }^{2}$ Department of Medical Ethics, Shiraz University of Medical \\ Sciences, Iran
}

Correspondence: Sedigheh Ebrahimi, Department of Medical Ethics, Shiraz University of Medical Sciences, Iran, Email sedighebrahimi@gmail.com

Received: October 28, 2020 | Published: November 19, 2021

\section{Letter to editor}

Dear Editor,

Hepatitis $\mathrm{C}$ virus (HCV) infection is among the leading causes of chronic liver disease, resulting in related morbidity and mortality, globally. ${ }^{1} \mathrm{HCV}$ is still remained endemic in several countries; and nearly four million new patients with $\mathrm{HCV}$ are diagnosed worldwide, annually. ${ }^{2}$ While the prescription of direct acting antiviral drugs (DAAs) has led to increased cure rates for many patients with HCV, there is still a demand for more promising treatments. ${ }^{3}$ Furthermore, many of the current approved medications are substantially expensive, and are accessible only in the privileged countries. ${ }^{4}$

The practice of complementary and alternative medicine (CAM) has increased worldwide, and CAM showed several beneficial effects for many chronic diseases. ${ }^{5}$ Moreover, many people tend to use CAM, including, Ayurveda, traditional Chinese medicine (TCM), and Unani medicine throughout the world, especially when the conventional treatments fail. According to a previous survey-based study, nearly $80 \%$ of patients with HCV infection had used CAM to improve their wellbeing and reduce the symptoms of the disease. ${ }^{6}$ These patients had tried acupuncture, meditation, and herbal supplements such as Ginseng, Echinacea, and Ginkgo biloba, Silybum marianum to improve their symptoms. ${ }^{7}$

The previous investigations have showed that several natural compounds could have hepatoprotective efficacies. ${ }^{8}$ As the extract of silymarin, the milk thistle plant (Silybum marianum), decreased the viral load of $\mathrm{HCV}$ and the fibrosis to cirrhosis progression in patients with chronic HCV infection..$^{9-11}$ Both in vitro and in vivo studies showed that the silymarin extract could improve HCV infection because of its anti-inflammatory and anti-viral properties. ${ }^{12-15}$ The green tea (Camellia sinensis) extract also showed a dose-dependent inhibitory effect on the HCV infection. ${ }^{16-18}$ Similarly, the grapefruit (naringenin) has showed a dose-dependent inhibition of HCV production. ${ }^{19,20}$ Moreover, oxymatrine supplementation inhibited $\mathrm{HCV}$ proliferation, antagonized liver fibrosis, and regulated immune functions in patients with chronic hepatitis C. ${ }^{21}$ The extract of shrubby sophora (Sophora flavescens) root, that is consisted of oxymatrine, had inhibitory effects on HCV infection in both in vitro and in vivo experiments. ${ }^{22-25}$ Although some of these medicinal herbs demonstrated anti-HCV activities in the previous experiments, their mechanisms of action and safety remain to be investigated.

Many CAMs including several medicinal herbs are used to alleviate liver disease; however, there is still insufficient evidence in this regard. Certain natural compounds can decrease the viral load of $\mathrm{HCV}$ and prevent further liver damage. While, some of these herbs do not have any therapeutic efficacy and may cause detrimental effects on the patients. Overall, it seems that these treatments are very popular among the general population, are more available, and have lower costs and side effects comparing to the conventional therapies. Besides, some of these medications showed promising therapeutic effects on HCV infection in preclinical and clinical studies. Hence over, we suggest that further investigations with higher methodological quality should be conducted regarding the treatment of hepatitis C using CAM.

\section{Acknowledgments}

None.

\section{Conflicts of interest}

The authors declare that there are no conflicts of interest.

\section{Funding}

None.

\section{References}

1. Kasraian L, Hosseini S, Salehi Marzijarani M, et al. The Prevalence of Hepatitis C Infection in Blood Donors: A Meta-Analysis and Systematic Review. Arch Virol. 2020;22(1):e94998.

2. Munir S, Saleem S, Idrees M, Tariq A, Butt S, Rauff B, et al. Hepatitis C Treatment: current and future perspectives. Virol J. 2010;7(1):296.

3. Brennan T, Shrank W. New Expensive Treatments for Hepatitis C Infection. JAMA. 2014;312(6):593-594.

4. Zoulim F, Liang TJ, Gerbes AL, et al. Hepatitis C virus treatment in the real world: optimising treatment and access to therapies. Gut. 2015;64(11):1824-1833.

5. Marzio DLH-D, Fenkel JM. Complementary and alternative medications in hepatitis C infection. World J Hepatol. 2014;6(1):9-16. 
6. Richmond JA, Bailey DE, Patel K, et al. The use of complementary and alternative medicine by patients with chronic hepatitis C. Complementary Therapies in Clinical Practice. 2010;16(3):124-131.

7. White CP, Hirsch G, Patel S, et al. Complementary and alternative medicine use by patients chronically infected with hepatitis $\mathrm{C}$ virus. Can J Gastroenterol. 2007;21(9):589-595.

8. Calland N, Dubuisson J, Rouillé Y, et al. Hepatitis C virus and natural compounds: a new antiviral approach? Viruses. 2012;4(10):2197-217.

9. Freedman ND, Curto TM, Morishima C, et al. Silymarin use and liver disease progression in the Hepatitis C Antiviral Long-Term Treatment against Cirrhosis trial. Aliment Pharmacol Ther. 2011;33(1):127-137.

10. Ferenci P, Scherzer TM, Kerschner H, et al. Silibinin Is a Potent Antiviral Agent in Patients With Chronic Hepatitis C Not Responding to Pegylated Interferon/Ribavirin Therapy. Gastroenterology. 2008;135(5):1561-1567.

11. Rutter K, Scherzer TM, Beinhardt S, et al. Intravenous silibinin as 'rescue treatment' for on-treatment non-responders to pegylated interferon ribavirin combination therapy. Antivir Ther. 2011;16(8):1327-1333.

12. Polyak SJ, Morishima $\mathrm{C}$, Shuhart $\mathrm{MC}$, et al. Inhibition of $\mathrm{T}-\mathrm{Cell}$ Inflammatory Cytokines, Hepatocyte NF- $\mathrm{kB}$ Signaling, and HCV Infection by Standardized Silymarin. Gastroenterology. 2007;132(5):1925-1936.

13. Wagoner J, Negash A, Kane OJ, Maet al. Multiple effects of silymarin on the hepatitis C virus lifecycle. Hepatology. 2010;51(6):1912-1921.

14. Wagoner J, Morishima C, Graf TN, et al. Differential in vitro effects of intravenous versus oral formulations of silibinin on the HCV life cycle and inflammation. PloS One. 2011;6(1):e16464.

15. Ashfaq UA, Javed T, Rehman S, et al. Inhibition of HCV 3a core gene through Silymarin and its fractions. Virol J. 2011;8(1):153.

16. Calland N, Albecka A, Belouzard S, et al. (-)-Epigallocatechin-3-gallate is a new inhibitor of hepatitis C virus entry. Hepatology. 2012;55(3):720 729.
17. Ciesek S, von Hahn T, Colpitts CC, et al. The green tea polyphenol, epigallocatechin-3-gallate, inhibits hepatitis C virus entry. Hepatology. 2011;54(6):1947-1955.

18. Chen C, Qiu H, Gong J, et al. (-)-Epigallocatechin-3-gallate inhibits the replication cycle of hepatitis C virus. Arch Virol. 2012;157(7):1301-1212.

19. Goldwasser J, Cohen PY, Lin W, et al. Naringenin inhibits the assembly and long-term production of infectious hepatitis $\mathrm{C}$ virus particles through a PPAR-mediated mechanism. J Hepatol. 2011;55(5):963-971.

20. Nahmias Y, Goldwasser J, Casali M, et al. Apolipoprotein B-dependent hepatitis $\mathrm{C}$ virus secretion is inhibited by the grapefruit flavonoid naringenin. Hepatology. 2008;47(5):1437-1445.

21. Li J, Li C, Zeng M. [Preliminary study on therapeutic effect of oxymatrine in treating patients with chronic hepatitis C]. Zhonghua Gan Zang Bing Za Zhi. 1998;18(4):227-229.

22. Chen XS, Wang GJ, Cai X, et al. Inhibition of hepatitis B virus by oxymatrine in vivo. World J Gastroenterol. 2001;7(1):49-52.

23. Chen Y, Li J, Zeng M, et al. [The inhibitory effect of oxymatrine on hepatitis C virus in vitro]. Zhonghua Gan Zang Bing Za Zhi. 2001;9 Suppl:12-14.

24. Dong XQ, Du Q, Yu WH, et al. Anti-inflammatory Effects of Oxymatrine Through Inhibition of Nuclear Factor-kappa B and Mitogen-activated Protein Kinase Activation in Lipopolysaccharide-induced BV2 Microglia Cells. Iran J Pharm Res. 2013;12(1):165-174.

25. Yang W, Zeng M, Fan Z, et al. [Prophylactic and therapeutic effect of oxymatrine on D-galactosamine-induced rat liver fibrosis]. Zhonghua Gan Zang Bing Za Zhi. 2002;10(3):193-196. 